\title{
The Role of Cognitive Motivation and Personality Traits in EFL Learners' Group Work Free Riding Tendencies: Teachers' and Learners' Attitudes
}

\section{Leila Ahmadpour}

Islamic Azad University Bonab Branch

Hassan Asadollahfam ( $\sim$ Asadollahfam@gmail.com )

Islamic Azad University Bonab Branch https://orcid.org/0000-0003-1643-3372

Davud Kuhi

Islamic Azad University of Maragheh

Keywords:

Posted Date: April 20th, 2020

DOI: https://doi.org/10.21203/rs.3.rs-21954/v1

License: (c) (i) This work is licensed under a Creative Commons Attribution 4.0 International License.

Read Full License 


\section{Abstract}

The authors have requested that this preprint be removed from Research Square. 